\title{
Workspace Disorder Does Not Influence Creativity and Executive Functions
}

\author{
Alberto Manzi ${ }^{1 *}$, Yana Durmysheva ${ }^{2}$, Shannon K. Pinegar ${ }^{3}$, Andrew Rogers ${ }^{1}$ and \\ Justine Ramos' ${ }^{1}$ \\ ${ }^{1}$ School of Social and Behavioral Sciences, Mercy College, Dobbs Ferry, NY, United States, ${ }^{2}$ Borough of Manhattan \\ Community College, City University of New York, New York, NY, United States, ${ }^{3}$ Baruch College, City University of New York, \\ New York, NY, United States
}

Recent research by Vohs et al. (2013) garnered media attention after reporting that disordered environments increase creativity. The present research was designed to conceptually replicate and extend this finding by exploring the effect of workspace disorder on creativity. Participants were randomly assigned to work at a neatly organized (Order condition) or a messy desk (Disorder condition), where they completed several paper-and-pencil and computerized tasks, including two validated creativity measures

\section{OPEN ACCESS}

Edited by:

Darya L. Zabelina,

University of Arkansas, United States

Reviewed by:

Alexander Strobel,

Technische Universität Dresden,

Germany

Bernard Arjan Nijstad, University of Groningen, Netherlands Marta Katarzyna Wronska, University of Groningen, Netherlands, in collaboration with reviewer BAN

${ }^{*}$ Correspondence: Alberto Manzi amanzi@mercy.edu

Specialty section: This article was submitted to Cognition,

a section of the journal Frontiers in Psychology

Received: 27 July 2018 Accepted: 11 December 2018 Published: 15 January 2019

Citation:

Manzi A, Durmysheva Y, Pinegar SK, Rogers A and Ramos J (2019) Workspace Disorder Does Not Influence Creativity and Executive

Functions. Front. Psychol. 9:2662. doi: 10.3389/fpsyg.2018.02662
(Abbreviated Torrance Test for Adults; ATTA; Goff and Torrance, 2002; Alternative Uses Task; adapted from Guilford, 1967). We also included several executive control measures from the NIH EXAMINER (Kramer, 2011), to explore the role of reduced top-down control in explaining a possible creativity-disorder connection. Independentsamples $t$-tests failed to replicate any significant difference in creativity between the Order and Disorder conditions. Furthermore, the conditions did not differentially affect executive control. Despite implementing an experimental setup similar to the one in Vohs et al. (2013), including a larger sample size, and adopting multiple measures of the constructs of interest, we did not find any effect of workspace clutter on cognitive performance. At this stage, the relationship between disorder and cognition seems elusive and does not warrant the claims it generated in the popular press.

Keywords: clutter, disorder, order, messy desk, creativity, divergent thinking, executive function

\section{INTRODUCTION}

Creativity involves thinking in novel, original and useful ways, and can manifest itself in many different contexts and activities (Runco, 2004). Although traditionally creativity has been viewed as a product of internal characteristics of the creator, in recent years researchers dedicated efforts to studying environmental influences on creative processes (Amabile and Pillemer, 2012). Among them are Vohs et al. (2013), who explored the role of environmental disorder on creativity. In their study, college students were administered an adaptation of the Alternative Uses Task (AUT; Guilford, 1967), and asked to generate as many alternative/unusual uses as possible for a ping-pong ball while sitting at a desk scattered with papers and books (Disorder condition) or neatly organized (Order condition). Indeed, those in the Disorder condition generated ideas rated as 0.41 points more creative on a 3-point scale than those in the Order condition. They also generated more highly creative ideas (scored 3 on a 3-point scale), though the total number of ideas was equivalent in the two groups. The authors speculated that a cluttered environment 
could implicitly prime an attitude of "breaking with tradition" (p. 1860), whereas a neat environment would prime the concept of "playing it safe" (p. 1866).

Despite media coverage going as far as advocating for messy desks at work (Vohs, 2013; Hill, 2018), these findings have yet to be replicated and need scientific attention. Therefore, we set out to explore why and how physical disorder would improve creative thinking. We hypothesized that a possible explanatory key might reside in the relationship between creativity and executive functioning, and how the latter may be influenced by cluttered environments. Evidence suggests that reduced topdown control may facilitate divergent thinking by enabling access to a broader range of nodes in the semantic network and allowing bottom-up processing, which is more exploratory and less guided by cognitive schemas (Vartanian et al., 2007; Beaty et al., 2016). Research showed increased creativity following experimental manipulations aimed at reducing cognitive control via neurostimulation of the frontal cortex (Chrysikou et al., 2013), after exposure to an experimental ego-depletion paradigm using a taxing executive control task (Radel et al., 2015), after bodily activities that exhaust control resources (Zhou et al., 2017) or in contexts that facilitate mind wandering and "open focus" (Baird et al., 2012; Colzato et al., 2017). Furthermore, in correlational studies, White and Shah $(2006,2011)$ reported that individuals with ADHD struggled to inhibit irrelevant information yet outperformed non-ADHD individuals in divergent thinking tasks. Also, those who generated looser semantic associations to word pairs (possibly due to weaker top-down control) produced more inventive creations (White and Shah, 2016; see also, Zabelina et al., 2016, on the relationship between divergent thinking performance and "flexible" attention).

Are executive functions drained by environmental disorder? And could this explain the disorder-creativity connection? Psychophysical research indicates that cluttered visual environments increase reaction times and decrease executive control regardless of whether this is assessed concurrently or after exposure (McMains and Kastner, 2011; McCarley et al., 2012). Berman et al. (2008) found that a stroll through a busy city street lowered executive control and working memory compared to a quiet park, with similar results induced by looking at pictures of nature compared to urban environments (therefore in contexts that did not require engagement or interaction with the environment, but simply exposure). Furthermore, in designs similar to the study by Vohs et al. (2013), Chae and Zhu (2014) assigned participants to orderly or disorderly workstations, although with clutter displayed vertically, behind and above the desk. The Disorder condition performed worse at the Stroop task and gave up sooner on an unsolvable puzzle task. It can be speculated that disorderly environments offer distractions, which compete for attentional resources. Inhibiting these distractions would increase the demand on the executive control system; therefore, resulting in reduced cognitive control compared to tidy environments.

The present study is aimed at further investigating the effect of cluttered work environments on creativity and executive control. The goal was to conceptually replicate the clutter effect on creativity (Vohs et al., 2013) using another measure of creativity (the Abbreviated Torrance Test for Adults; ATTA; Goff and Torrance, 2002) in addition to the AUT. Concurrently, we tested the effect of clutter on different measures of executive control to explore the role of executive functioning in the disorder-creativity connection. We also included individual differences measures of personality and sensitivity to perceptual context (field dependence-independence), as these might help understand the differences in susceptibility to the effect of environmental disorder and serve to assure group equivalence.

\section{METHODS}

\section{Participants}

One-hundred and fourteen volunteers participated in the study. After exclusions due to data corruption or non-compliance, a final sample of 100 was retained (Age: $M=22.89, S D=5.19 ; 69 \%$ female; $81 \%$ right-handed; see demographics in Supplementary Material). Participants were compensated with a US\$20 gift card or extra credit. The study was approved by Mercy College Institutional Review Board, and informed consent was obtained prior to entry into this study.

\section{Measures}

The protocol included paper-and-pencil and computerized tests assessing personality, cognitive style, creative divergent thinking, and executive functions (for additional details, see Supplementary Material).

The NEO-Five Factor Inventory 3 (NEO-FFI-3; Mccrae and Costa, 2004) was used to assess the Big Five personality domains: Neuroticism, Extraversion, Openness, Agreeableness, and Conscientiousness. The Group Embedded Figures Test (GEFT; Witkin et al., 1971) measured field independence, the cognitive style related to visually perceiving an element as separate from its context.

The Alternative Uses Task (AUT; adapted from Guilford, 1967) was administered to measure divergent thinking and creativity, by asking participants to write up to 10 alternative/unusual uses for an automobile tire in $5 \mathrm{~min}$. Inappropriate responses were rejected and identical/overlapping entries were coded as repetitions. Two raters blind to experimental condition assessed creativity holistically on a 5 -point scale by considering commonality, remoteness and cleverness [see scoring directions in Silvia et al. (2008)]. To avoid that very similar responses were not assigned different creativity scores, the final pool of pertinent responses (referred to as "fluency" in the results' tables) was sorted in homogenous categories (e.g., gardening, furniture, etc.) and then judged for creativity. Inter-rater reliability on creativity scores was high as scores assigned by the two raters were very highly correlated [Pearson's $r=0.92 ; p<0.001$ ].

The Abbreviated Torrance Tests for Adults (ATTA; Goff and Torrance, 2002) was also administered to obtain additional measures of verbal and figural creativity. The first task (ATTA 1) asked participants to list possible problems associated with being able to fly or walk on air. Scoring followed the procedure outlined for the AUT and resulted in very high inter-rater correlation 
$[r=0.98 ; p<0.001]$. In the second task (ATTA 2) participants used two incomplete abstract figures to create two drawings and give them a title. Similarly, in the third task (ATTA 3) participants used 9 triangles arranged in a $3 \times 3$ matrix to draw pictures and title them. Creativity was scored as described above and reliability was good $[r>0.90 ; p<0.001 ; r=0.74, p<0.001$, respectively]. Overall, for all creativity tasks, the high inter-rater correlations indicated that scorers adopted similar criteria to assess creativity. To honor the slight differences in creativity ratings produced by the two raters, scores were averaged before data analysis.

To assess different aspects of executive functioning, the following NIH EXAMINER subtests (Kramer, 2011 ${ }^{1}$ ) were used: Letter Fluency (L, F) and Category Fluency (animals, vegetables) in 1-min blocks; Set Shifting, requiring responding to the shape or the color of bivalent stimuli in homogenous or intermixed blocks of trials to compute "mixing costs" (RT difference between mixed-task blocks and single-task blocks) and "switching costs" (RT slowing when switching tasks in a mixed block; Monsell, 2003); Flanker Task, Digit Span Task (verbal working memory), and N-back Task (visuo-spatial working memory) (see tasks descriptions and scoring criteria in Supplementary Material).

\section{Procedure}

Participants were tested individually in two adjacent identical classrooms at Mercy College in New York City. They were first placed in a neutral environment, identical for both conditions, to complete informed consent, personality and cognitive style measures. Then, they were directed to the workspace, where desk materials and chairs were arranged in an orderly or disorderly fashion (see Figure 1). Here, after a 3-min delay, the remaining tasks were administered. Task order was counterbalanced between participants with a 5 -min break scheduled midpoint in the session. Upon completion, participants were debriefed and compensated.

\section{RESULTS}

Conditions were equivalent for demographic and individual differences of the participants (see Supplementary Material). Independent-samples $t$-tests were conducted to compare the

${ }^{1}$ https://memory.ucsf.edu/examiner-assessments

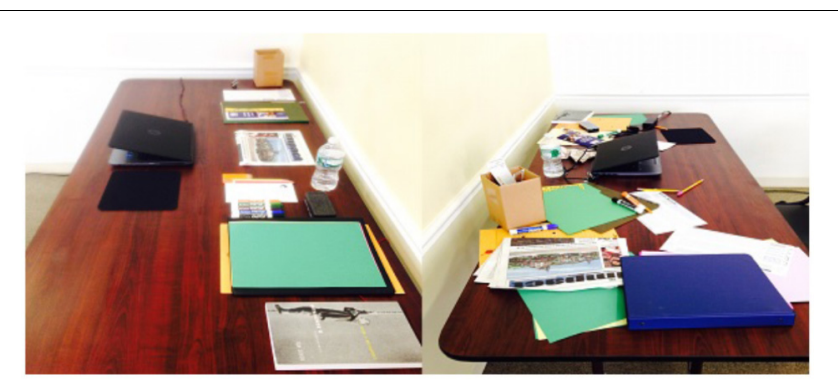

FIGURE 1 | Workspace setup for the Order (left) and the Disorder (right) conditions. creativity and executive function measures between the Order and Disorder conditions (see Table 1). A Bonferroni-corrected alpha-level was set at 0.0125 , given the four creativity and four executive measures being compared, respectively. The number of titles produced at the ATTA 2, and the number of figures and titles for ATTA 3 returned the smallest $p$-values and largest effects ( $p=0.09, p=0.05$, and $p=0.09$, respectively; see Table 1 ). However, these trends should be interpreted with caution because they were isolated and greater than the adopted significance cutoff. No condition differences were found for the average creativity ratings for all creativity tasks, even when these values were collapsed in an overall creativity measure obtained by averaging the standardized scores for all four variables.

All Order-Disorder comparisons were not significant also in the case of the executive functioning measures (see Table 1).

Results remained unchanged after removing outliers scores 3 SD away from the mean $(n=5)$.

\section{Ancillary Analysis}

A series of additional analyses were conducted to test differences between task rotations. We also compared the effect of experimental conditions only considering the rotations that most closely resembled the task order in Vohs et al. (2013) and Chae and Zhu (2014). Finally, we explored possible interaction effects between condition and executive control. These results are discussed in the Supplementary Material available online.

\section{DISCUSSION}

Our design employed a multi-measure approach to conceptually replicate and extend previous findings showing increased creativity in messy workspaces (Vohs et al., 2013). We included verbal and figural creativity tasks, as well as various executive functioning tasks to investigate the possible role of reduced top-down control in explaining a possible creativity-disorder connection. We hypothesized that a cluttered work environment would interfere with executive functioning, reducing top-down control and increasing access to a broader semantic network; thus, allowing participants to generate more creative ideas. Moreover, in keeping with recent statistical guidelines for sound replication studies (Simonsohn, 2015), we employed a sample twice as large as the one in the study by Vohs et al. (2013). Results in our study indicated that working at a messy desk did not result in significantly and reliably different creativity or executive functioning performance. Despite being confident that our design was not underpowered, we can identify some limitations that might explain the lack of significant differences between the Order and the Disorder conditions. For example, Vohs et al. (2013) asked participants to develop alternative uses for a ping-pong ball, whereas we used an automobile tire; they used a 3-point creativity rating scale whereas we used a 5-point scale. Nevertheless, the literature abounds of multiple variations on objects used in the alternative uses tasks [e.g., brick, shoe, newspaper, paper clip; see also the original task instructions by Guilford (1967)] and the scoring 
TABLE 1 | Creativity and executive function measures, separately for the Order and Disorder conditions.

\begin{tabular}{|c|c|c|c|c|c|c|}
\hline \multirow[t]{2}{*}{ Variables } & \multicolumn{2}{|c|}{ Order } & \multicolumn{2}{|c|}{ Disorder } & \multirow[t]{2}{*}{ Statistics $^{1}$} & \multirow[t]{2}{*}{ Cohen's $d[\mathrm{Cl}]^{2}$} \\
\hline & M (SD) & [Cl] & M (SD) & {$[\mathrm{Cl}]$} & & \\
\hline \multicolumn{7}{|l|}{ Alternative Uses Task (AUT) } \\
\hline Fluency & $5.52(2.78)$ & {$[4.72,6.31]$} & $6.32(2.53)$ & {$[5.60,7.04]$} & $t(98)=-1.504, p=0.14$ & $0.30[-0.09,0.69]$ \\
\hline Rejected responses & $1.02(2.00)$ & {$[0.45,1.59]$} & $0.90(1.74)$ & {$[0.41,1.39]$} & $t(98)=0.320, p=0.75$ & $-0.06[-0.46,0.33]$ \\
\hline Repetitions & $0.26(0.63)$ & {$[0.08,0.44]$} & $0.30(0.58)$ & {$[0.13,0.46]$} & $t(98)=-0.329, p=0.74$ & $0.06[-0.33,0.46]$ \\
\hline Creativity average & $2.80(0.35)$ & {$[2.7,2.90]$} & $2.68(0.47)$ & {$[2.55,2.81]$} & $t(92)=1.365, p=0.18$ & $-0.29[-0.68,0.11]$ \\
\hline Highly creative ideas & $1.34(1.29)$ & {$[0.97,1.71]$} & $1.10(1.07)$ & {$[0.79,1.41]$} & $t(98)=1.012, p=0.31$ & $-0.20[-0.60,0.19]$ \\
\hline \multicolumn{7}{|l|}{ ATTA - subtest 1} \\
\hline Fluency & $4.84(1.82)$ & {$[4.32,5.36]$} & $4.92(2.06)$ & {$[4.33,5.51]$} & $t(98)=-0.206, p=0.84$ & $0.04[-0.35,0.43]$ \\
\hline Rejected responses & $0.90(1.42)$ & {$[0.50,1.30]$} & $0.58(1.20)$ & {$[0.24,0.92]$} & $t(98)=1.220, p=0.23$ & $-0.24[0.64,0.15]$ \\
\hline Repetitions & $0.32(0.54)$ & {$[0.17,0.47]$} & $0.30(0.71)$ & {$[0.10,0.50]$} & $t(98)=0.158, p=0.86$ & $-0.03[-0.42,0.36]$ \\
\hline Creativity average & $2.45(0.84)$ & {$[2.21,2.69]$} & $2.55(0.82)$ & {$[2.32,2.78]$} & $t(98)=-0.581, p=0.56$ & $0.12,[0.27,0.51]$ \\
\hline Highly creative ideas & $1.64(1.53)$ & {$[1.20,2.08]$} & $1.64(1.340)$ & {$[1.26,2.02]$} & $t(98)=0.000, p=1.00$ & $0.00[-0.39,0.39]$ \\
\hline \multicolumn{7}{|l|}{ ATTA - subtest 2} \\
\hline Fluency (figures) & $1.74(0.53)$ & {$[1.59,1.89]$} & $1.96(0.81)$ & {$[1.72,2.19]$} & $t(98)=-1.614, p=0.11$ & $0.32[-0.07,0.71]$ \\
\hline Fluency (titles) & $1.50(0.71)$ & {$[1.30,1.70]$} & $1.78(0.91)$ & {$[1.52,2.04]$} & $t(98)=-1.718, \underline{p=0.09}$ & $0.34[-0.05,0.74]$ \\
\hline Creativity average & $2.15(0.13)$ & {$[2.11,2.18]$} & $2.33(0.90)$ & {$[2.07,2.58]$} & $t(95)=-0.979, p=0.33$ & $0.28[-0.12,0.67]$ \\
\hline Highly creative ideas & $0.46(1.03)$ & {$[0.17,0.75]$} & $0.66(1.27)$ & {$[0.30,1.02]$} & $t(98)=-0.863, p=0.39$ & $0.17[-0.22,0.57]$ \\
\hline \multicolumn{7}{|l|}{ ATTA - subtest 3} \\
\hline Fluency (figures) & $2.68(2.20)$ & {$[2.05,3.31]$} & $3.56(2.13)$ & {$[2.95,4.17]$} & $t(98)=-2.033, \underline{p=0.05}$ & $0.41[0.01,0.80]$ \\
\hline Fluency (titles) & $2.48(2.23)$ & {$[1.85,3.12]$} & $3.22(2.06)$ & {$[2.64,3.81]$} & $t(98)=-1.721, p=0.09$ & $0.65[-0.05,0.74]$ \\
\hline Creativity average & $2.18(0.89)$ & {$[1.92,2.43]$} & $2.26(0.83)$ & {$[2.02,2.50]$} & $t(93)=-0.466, p=0.64$ & $0.09[-0.30,0.49]$ \\
\hline Highly creative ideas & $0.28(0.70)$ & {$[0.08,0.48]$} & $0.26(0.53)$ & {$[0.11,0.41]$} & $t(98)=0.161, p=0.87$ & $-0.03[-0.42,0.36]$ \\
\hline Overall creativity average (z) & $-0.03(0.56)$ & {$[-0.19,0.13]$} & $0.00(0.62)$ & {$[-0.17,0.18]$} & $t(98)=-0.314, p=0.75$ & $0.06[-0.33,0.46]$ \\
\hline \multicolumn{7}{|l|}{ Flanker task } \\
\hline Error difference & $0.78(2.10)$ & {$[0.18,1.38]$} & $0.78(2.52)$ & {$[0.06,1.50]$} & $t(98)=0.000, p=1.00$ & $0.00[-0.39,0.39]$ \\
\hline Median RT Difference & $0.16(0.13)$ & {$[0.12,0.20]$} & $0.15(0.11)$ & {$[0.12,0.18]$} & $t(98)=0.423, p=0.67$ & $0.08[-0.48,0.31]$ \\
\hline \multicolumn{7}{|l|}{ Set-shifting task } \\
\hline Mixing cost median RT & $0.28(0.26)$ & {$[0.21,0.35]$} & $0.20(0.23)$ & {$[0.13,0.27]$} & $t(97)=1.629, p=0.11$ & $-0.33[-0.72,0.07]$ \\
\hline Switching cost median RT & $0.11(0.12)$ & {$[0.08,0.14]$} & $0.10(0.12)$ & {$[0.07,0.13]$} & $t(97)=0.305, p=0.76$ & $-0.08[-0.48,0.31]$ \\
\hline \multicolumn{7}{|l|}{ Working memory } \\
\hline 1-Back errors & $2.78(1.84)$ & {$[2.26,3.30]$} & $3.36(2.22)$ & {$[2.73,3.99]$} & $t(98)=-1.421, p=0.16$ & $0.28[-0.11,0.68]$ \\
\hline 2-Back errors & $23.58(9.3)$ & {$[20.94,26.22]$} & $25.36(10.5)$ & {$[22.3,28.3]$} & $t(91)=-0.863, p=0.39$ & $0.18[-0.21,0.57]$ \\
\hline Dot-counting span & $4.44(1.30)$ & {$[4.07,4.81]$} & $4.02(1.46)$ & {$[3.61,4.43]$} & $t(98)=1.519, p=0.13$ & $-0.30[-0.70,0.09]$ \\
\hline \multicolumn{7}{|l|}{ Fluency } \\
\hline Letter - correct & $21.96(5.3)$ & {$[20.45,23.47]$} & $22.98(7.2)$ & {$[20.9,25.0]$} & $t(90.1)^{3}=-0.806, p=0.42$ & $0.16[-0.23,0.55]$ \\
\hline Letter - repetitions & $0.14(0.41)$ & {$[0.02,0.27]$} & $0.22(0.58)$ & {$[0.06,0.38]$} & $t(98)=-0.798, p=0.43$ & $0.16[-0.23,0.55]$ \\
\hline Letter - violations & $0.36(0.85)$ & {$[0.12,0.60]$} & $0.60(1.03)$ & {$[0.31,0.89]$} & $t(98)=-1.270, p=0.21$ & $0.25[-0.14,0.65]$ \\
\hline Category - correct & $28.12(6.7)$ & {$[26.22,30.02]$} & $29.18(8.5)$ & {$[26.76,31.60]$} & $t(98)=-0.693, p=0.49$ & $0.14[-0.25,0.53]$ \\
\hline Category - repetitions & $0.54(0.97)$ & {$[0.26,0.81]$} & $0.34(0.96)$ & {$[0.07,0.61]$} & $t(98)=1.034, p=0.30$ & $-0.21[-0.60,0.19]$ \\
\hline Category - violations & $0.62(1.19)$ & {$[0.28,0.95]$} & $1.68(3.46)$ & {$[0.70,2.66]$} & $t(60.5)^{3}=-2.05, p=0.05$ & $0.41[0.01,0.81]$ \\
\hline
\end{tabular}

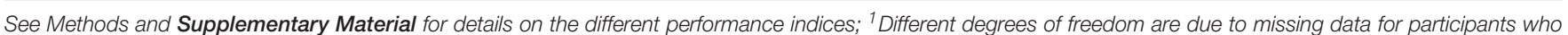

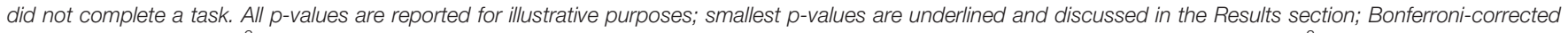

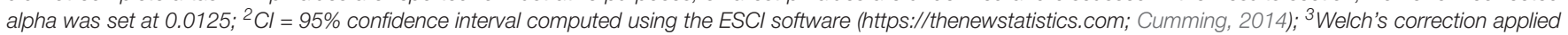

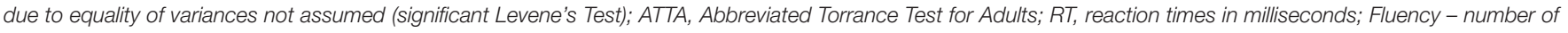

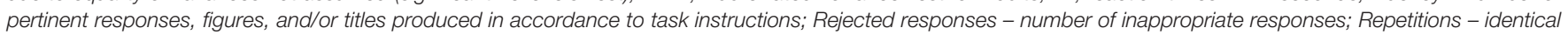

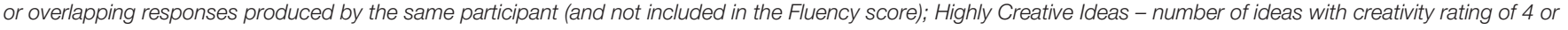
5 on a 5-point scale.

protocol we followed has been widely investigated and does not warrant radically different results. Most importantly, we employed multiple creativity measures, covering the spectrum of verbal and figural creative abilities; therefore, it is compelling that none of the measures showed the expected effect. Similarly, we noted certain differences between our study and the one by Chae and Zhu (2014), who reported an effect of disorder on executive functioning (overall RT at the Stroop task) and perseverance (time spent working on an unsolvable puzzle). Indeed, the authors used a more salient environmental manipulation, with 
clutter being displayed on the wall above and behind the participant's desk [compared to objects spread across the table in our case and in the study by Vohs et al. (2013)], which might have resulted in a more powerful disruption of topdown control. Additionally, in two of the studies by Chae and Zhu (2014), participants remained in the manipulated environment when completing surveys (therefore, for longer than the 3-min delay in our study) before measuring executive functioning/perseverance. Furthermore, they explicitly asked participants about their perception of the room organization, increasing participant attention to the environment and possibly making the manipulation more effective.

Sample size remains one compelling difference between our study and the studies cited above, as both studies only included 20 to 25 participant per group. Outliers have a greater influence on groups with a smaller sample, a problem that we tried to minimize by doubling our sample sizes per group $(n=50)$. Since the authors do not report outlier analyses or detailed descriptive statistics, we speculate whether their results would persist with a broader sample.

In addition to the differences in experimental design discussed above, our participants may also perform differently because they score differently on individual difference measures. Indeed, exploratory post hoc analysis (see Supplementary Material) found an interaction between condition and executive function, pointing to a small condition effect (better creativity in the disorder condition) for those with better executive control. We caution against over reliance on this finding, as only one of the several executive function measures reflected this effect. Yet, the trend supports Vohs et al. (2013), and we can concede that overall differences in executive functioning between the two samples could potentially explain the different results. Unfortunately, the original study by Vohs et al. (2013) did not include descriptive statistics on individual differences, therefore our alternative explanation remains speculative.

Finally, we failed to ask our participants about their perceived sensitivity to disorder or preference toward workspace tidiness. Participants' aversive reaction to cluttered environment might cause disengagement and lead participants to implement less topdown control, which could provide an alternative mechanism to understand the effect of clutter on cognitive performance. Unfortunately, we lack data on how participants' reaction to the disorder manipulation (or lack thereof) might have contributed to our results.

Overall, given the limitations reviewed above, we believe that future research on the creativity-disorder connection should use manipulations leading to different levels of executive control

\section{REFERENCES}

Amabile, T. M., and Pillemer, J. (2012). Perspectives on the social psychology of creativity. J. Creat. Behav. 46, 3-15. doi: 10.1002/jocb.001

Baird, B., Smallwood, J., Mrazek, M. D., Kam, J. Y., Franklin, M. S., and Schooler, J. W. (2012). Inspired by distraction: mind wandering facilitates creative incubation. Psychol. Sci. 23, 1117-1122. doi: 10.1177/09567976124 46024 draining or interference, include groups with high/low executive functioning, as well as implement more salient, persistent, and interactive exposure to the manipulated environment. It would also be informative to measure the preference and tolerance for clutter and disorder of each participant.

Failed replications pose a great challenge to science, as they might lead to dichotomous interpretations, that either the original study was wrong, or that the replication was inaccurate. We prefer to avoid extreme verdicts. Yet, we are confident in concluding that, given the variety of measures used and the sample size of our study, the effect of working at a disorderly desk for a limited span of time - if true - is small and unreliable. At the current stage of the scientific inquiry on this topic, such elusive phenomenon does not warrant the sensationalistic claims it generated in the popular press.

\section{AUTHOR CONTRIBUTIONS}

$\mathrm{AM}$ and $\mathrm{YD}$ contributed to design, implementation, data collection, data analysis, and manuscript preparation. SP contributed to data analysis and manuscript preparation. AR and JR were responsible for data collection, data scoring, and assistance with manuscript preparation.

\section{FUNDING}

Funding for the study was provided by grant P031C110179 from the United States Department of Education's Title III, Part F HSI STEM and Articulation Program and by Mercy College Faculty Development Grants (2014-2018).

\section{ACKNOWLEDGMENTS}

We would like to thank the Mercy College and Borough of Manhattan Community College undergraduate research assistants for their help in data collection and data processing as part of the "Step Up to STEM" research program, Directed Research courses, and volunteer work.

\section{SUPPLEMENTARY MATERIAL}

The Supplementary Material for this article can be found online at: https://www.frontiersin.org/articles/10.3389/fpsyg. 2018.02662/full\#supplementary-material

Beaty, R. E., Benedek, M., Silvia, P. J., and Schacter, D. L. (2016). Creative cognition and brain network dynamics. Trends Cogn. Sci. 20, 87-95. doi: 10.1016/j.tics. 2015.10.004

Berman, M. G., Jonides, J., and Kaplan, S. (2008). The cognitive benefits of interacting with nature. Psychol. Sci. 19, 1207-1212. doi: 10.1111/j.1467-9280. 2008.02225.x

Chae, B., and Zhu, R. (2014). Environmental disorder leads to self-regulatory failure. J. Consum. Res. 40, 1203-1218. doi: 10.1086/674547 
Chrysikou, E. G., Hamilton, R. H., Coslett, H. B., Datta, A., Bikson, M., and Thompson-Schill, S. L. (2013). Noninvasive transcranial direct current stimulation over the left prefrontal cortex facilitates cognitive flexibility in tool use. Cogn. Neurosci. 4, 81-89. doi: 10.1080/17588928.2013.76 8221

Colzato, L. S., Szapora, A., Lippelt, D., and Hommel, B. (2017). Prior meditation practice modulates performance and strategy use in convergent- and divergent-thinking problems. Mindfulness 8, 10-16. doi: 10.1007/s12671-014-0 $352-9$

Cumming, G. (2014). The new statistics: why and how. Psychol. Sci. 25, 7-29. doi: $10.1177 / 0956797613504966$

Goff, K., and Torrance, E. P. (2002). Abbreviated Torrance Test for Adults. Bensenville, IL: Scholastic Testing Service, Inc.

Guilford, J. P. (1967). The Nature of Human Intelligence. New York, NY: McGrawHill.

Hill, A. (2018). Tidy Desks Challenge Messy Creativity. Financial Times. Available at: https://www.ft.com/content/fc512cfc-5431-11e8-b3ee-41e0209208ec

Kramer, J. (2011). Executive Abilities: Measures and Instruments for Neurobehavioral Evaluation and Research (EXAMINER). Available at: http://examiner.ucsf.edu/EXAMINER\%20User\%20Manual.pdf

McCarley, J. S., Yamani, Y., Kramer, A. F., and Mounts, J. W. (2012). Age, clutter, and competitive selection. Psychol. Aging 27, 616-626. doi: 10.1037/a0026705

Mccrae, R. R., and Costa, P. T. (2004). A contemplated revision of the NEO fivefactor inventory. Pers. Individ. Differ. 36, 587-596. doi: 10.1016/S0191-8869(03) 00118-1

McMains, S., and Kastner, S. (2011). Interactions of top-down and bottom-up mechanisms in human visual cortex. J. Neurosci. 31, 587-597. doi: 10.1523/ JNEUROSCI.3766-10.2011

Monsell, S. (2003). Task switching. Trends Cogn. Sci. 7, 134-140. doi: 10.1016/ S1364-6613(03)00028-7

Radel, R., Davranche, K., Fournier, M., and Dietrich, A. (2015). The role of (dis)inhibition in creativity: decreased inhibition improves idea generation. Cognition 134, 110-120. doi: 10.1016/j.cognition.2014. 09.001

Runco, M. A. (2004). Creativity. Annu. Rev. Psychol. 55, 657-687. doi: 10.1146/ annurev.psych.55.090902.141502

Silvia, P. J., Winterstein, B. P., Willse, J. T., Barona, C. M., Cram, J. T., Hess, K. I., et al. (2008). Assessing creativity with divergent thinking tasks: exploring the reliability and validity of new subjective scoring methods. Psychol. Aesthet. Creat. Arts 2, 68-85. doi: 10.1037/1931-3896.2.2.68
Simonsohn, U. (2015). Small telescopes: detectability and the evaluation of replication results. Psychol. Sci. 26, 559-569. doi: 10.1177/0956797614567341

Vartanian, O., Martindale, C., and Kwiatkowski, J. (2007). Creative potential, attention, and speed of information processing. Pers. Individ. Differ. 43, 1470-1480. doi: 10.1016/j.paid.2007.04.027

Vohs, K. D. (2013). It's Not Mess. It's Creativity. New York Times. Available at: http://www.nytimes.com/2013/09/15/opinion/sunday/its-not-mess-itscreativity.html?_r=0

Vohs, K. D., Redden, J. P., and Rahinel, R. (2013). Physical order produces healthy choices, generosity, and conventionality, whereas disorder produces creativity. Psychol. Sci. 24, 1860-1867. doi: 10.1177/0956797613480186

White, H. A., and Shah, P. (2006). Uninhibited imaginations: creativity in adults with attention-deficit/hyperactivity disorder. Pers. Individ. Differ. 40, 1121-1131. doi: 10.1016/j.paid.2005.11.007

White, H. A., and Shah, P. (2011). Creative style and achievement in adults with attention-deficit/hyperactivity disorder. Pers. Individ. Differ. 50, 673-677. doi: $10.1016 /$ j.paid.2010.12.015

White, H. A., and Shah, P. (2016). Scope of semantic activation and innovative thinking in college students with ADHD. Creat. Res. J. 28, 275-282. doi: 10. 1080/10400419.2016.1195655

Witkin, H. A., Oilman, F. K., Raskin, E., and Karp, S. (1971). A Manual for the Embedded Figures Test. Palo Alto, CA: Consulting Psychologists Press.

Zabelina, D., Saporta, A., and Beeman, M. (2016). Flexible or leaky attention in creative people? Distinct patterns of attention for different types of creative thinking. Mem. Cogn. 44, 488-498. doi: 10.3758/s13421-015-0569-4

Zhou, Y., Zhang, Y., Hommel, B., and Zhang, H. (2017). The impact of bodily states on divergent thinking: evidence for a control-depletion account. Front. Psychol. 8:1546. doi: 10.3389/fpsyg.2017.01546

Conflict of Interest Statement: The authors declare that the research was conducted in the absence of any commercial or financial relationships that could be construed as a potential conflict of interest.

Copyright (c) 2019 Manzi, Durmysheva, Pinegar, Rogers and Ramos. This is an openaccess article distributed under the terms of the Creative Commons Attribution License (CC BY). The use, distribution or reproduction in other forums is permitted, provided the original author(s) and the copyright owner(s) are credited and that the original publication in this journal is cited, in accordance with accepted academic practice. No use, distribution or reproduction is permitted which does not comply with these terms. 